\title{
Serum vascular endothelial growth factor as a marker of asthma exacerbation
}

\author{
Joo-Hee Kim
}

Department of Medicine, Hallym University Sacred Heart Hospital, Anyang, Korea
Received: February 16, 2017 Accepted: February 23, 2017

\author{
Correspondence to \\ Joo-Hee Kim, M.D. \\ Division of Pulmonary, Allergy, \\ and Critical Care Medicine, \\ Department of Medicine, \\ Hallym University Sacred Heart \\ Hospital, 22 Gwanpyeong-ro \\ 17obeon-gil, Dongan-gu, Anyang \\ 14068, Korea \\ Tel: $+82-31-380-3719$ \\ Fax: +82-31-380-3973 \\ E-mail: luxjhee@hallym.or.kr
}

\section{See Article on Page 295-301}

Asthma is the most common inflammatory disease of the lungs. Despite advances in management and widespread use of inhaled corticosteroids (ICS), acute exacerbations remain a relatively frequent event for many asthmatics [1]. Asthma exacerbation has serious effects on individual patients with significant reductions in quality of life, medical costs, and long-term declines in lung function [2].

Progressive lung function deterioration is a consequence of airway remodeling caused by chronic airway inflammation, tissue injury, and abnormal repair [3]. Angiogenesis has been recognized as an important step in the development and perpetuation of airway inflammation and tissue remodeling [4,5]. Vascular endothelial growth factor (VEGF) plays a fundamental role in the physiological and pathophysiological forms of angiogenesis. During airway growth, the lung acquires a rich blood supply, which is regulated by a balance of proangiogenic growth factors and angiostatic proteins. However, during chronic inflammation, VEGF stimulates angiogenesis and edema, and induces Th2 and eosinophilic inflammation, mucus metaplasia, subepithelial fibrosis, myocyte hyperplasia, and dendritic cell activation.

Because of its diverse properties in airway inflammation, the involvement of VEGF in asthmatic subjects has been investigated extensively. Asai et al. [6] reported that increased VEGF levels in induced sputum of asthmatic patients were associated with the degree of airway vascular permeability. Feltis et al. [7] examined VEGF in bronchoalveolar lavage fluid from adult asthma patients and normal controls, and found that VEGF levels increased in proportion to vessel number and density in asthmatics. Siddiqui et al. [8], in a bronchoscopic and sputum study, demonstrated an increase in vessels and VEGF in the lamina propria of airway biopsies, which became greater according to asthma severity.

In the current issue of the Korean Journal of Internal Medicine, Lee et al. [9] evaluated the clinical meaning of serum VEGF in asthmatics and normal controls, and compared its level during an asthma attack with that in a stable status. The authors collected lung function tests and asthma control test (ACT) scores. They also obtained serial serum samples from patients with exacerbations requiring hospital admission, from the onset of the attack to the recovery period. They found that serum VEGF was elevated in stable asthmatics and more elevated in patients during acute exacerbations compared to normal controls. Although they did not 
find a statistically significant association between ACT score and VEGF, they noted a tendency toward a correlation between the two markers. In particular, serum VEGF levels in patients having exacerbations decreased in accordance with clinical improvements, suggesting that serum VEGF could be a surrogate marker for monitoring asthma exacerbations. Lee et al. [10] also found that serum VEGF was significantly increased in stable asthmatic patients and even higher in acute asthmatic patients compared with the levels in healthy control subjects. Zou et al. [11] confirmed that serum VEGF levels were higher in patients with severe asthma compared to mild-to-moderate asthma patients or normal controls. However, the range of serum VEGF differed markedly among these studies. In the current study, the mean VEGF level in stable asthma patients was $177 \mu \mathrm{g} / \mathrm{mL}$, which is approximately half of the mean value reported by Lee et al. [10]. Zou et al. [11] reported a VEGF level of approximately one third of that observed in the current study. Therefore, it is important to develop a validation process to establish cut-off values and normal ranges, as well as standardized measurement techniques, to use serum VEGF as a marker of asthma exacerbation [12]. In the present study, VEGF was measured in blood samples due to ease of access in a clinical setting, but the cellular sources of VEGF in the peripheral blood of asthma patients were not investigated extensively. Eosinophils have been suggested as the main sources of peripheral VEGF [13], but other cellular components including neutrophils and platelets may also be important compartments for circulating VEGF [14]. Additionally, a variety of systemic factors are known to affect the level of VEGF [15]. Another weak point of the present study is that all subjects were young male asthmatics, causing a gender and age bias.

ICS is the most effective anti-asthma drug and affects airway vascularity through an inhibitory effect on immune cells expressing proangiogenic molecules [4]. Nevertheless, there is an unmet need in current asthma treatment: different phenotypes may respond differently to targeted therapies. Targeted therapies include antibodies, soluble receptors, and cytokines that drive inflammatory responses in the asthmatic lung [1]. Some effort has been made to inhibit VEGF or block its receptors, but benefits have only been demonstrated in animal experiments $[4,5]$. Serum VEGF levels are higher in patients with the severe or eosinophilic phenotype, compared with those with the mild-to-moderate or neutrophilic phenotype $[10,11]$. In the present study, a significant association was observed between serum VEGF and acute exacerbations in asthmatics. These findings suggest the possibility of using VEGF as a surrogate marker for monitoring exacerbation status or predicting the efficacy of specific therapies. However, further prospective and larger studies are required to support the use of the serum VEGF as a marker for asthma in clinical practice.

\section{Conflict of interest}

No potential conflict of interest relevant to this article was reported.

\section{REFERENCES}

1. Fajt ML, Wenzel SE. Development of new therapies for severe asthma. Allergy Asthma Immunol Res 2017;9:3-14.

2. Jackson DJ, Sykes A, Mallia P, Johnston SL. Asthma exacerbations: origin, effect, and prevention. J Allergy Clin Immunol 2011;128:1165-1174.

3. Pascual RM, Peters SP. Airway remodeling contributes to the progressive loss of lung function in asthma: an overview. J Allergy Clin Immunol 2005;116:477-486.

4. Detoraki A, Granata F, Staibano S, Rossi FW, Marone G, Genovese A. Angiogenesis and lymphangiogenesis in bronchial asthma. Allergy 2010;65:946-958.

5. Ribatti D, Puxeddu I, Crivellato E, Nico B, Vacca A, Levi-Schaffer F. Angiogenesis in asthma. Clin Exp Allergy 2009;39:1815-1821.

6. Asai K, Kanazawa H, Kamoi H, Shiraishi S, Hirata K, Yoshikawa J. Increased levels of vascular endothelial growth factor in induced sputum in asthmatic patients. Clin Exp Allergy 2003;33:595-599.

7. Feltis BN, Wignarajah D, Zheng L, et al. Increased vascular endothelial growth factor and receptors: relationship to angiogenesis in asthma. Am J Respir Crit Care Med 2006;173:1201-1207.

8. Siddiqui S, Sutcliffe A, Shikotra A, et al. Vascular remodeling is a feature of asthma and nonasthmatic eosinophilic bronchitis. J Allergy Clin Immunol 2007;120:813-819.

9. Lee HY, Min KH, Lee SM, Lee JE, Rhee CK. Clinical significance of serum vascular endothelial growth factor 
in young male asthma patients. Korean J Intern Med 2017;32:295-301.

10. Lee KY, Lee KS, Park SJ, et al. Clinical significance of plasma and serum vascular endothelial growth factor in asthma. J Asthma 2008;45:735-739.

11. Zou H, Fang QH, Ma YM, Wang XY. Analysis of growth factors in serum and induced sputum from patients with asthma. Exp Ther Med 2014;8:573-578.

12. Pavord ID, Afzalnia S, Menzies-Gow A, Heaney LG. The current and future role of biomarkers in type 2 cytokine-mediated asthma management. Clin Exp Allergy 2017;47:148-160.
13. Puxeddu I, Alian A, Piliponsky AM, Ribatti D, Panet A, Levi-Schaffer F. Human peripheral blood eosinophils induce angiogenesis. Int J Biochem Cell Biol 2005;37:628636.

14. Kusumanto YH, Dam WA, Hospers GA, Meijer C, Mulder $\mathrm{NH}$. Platelets and granulocytes, in particular the neutrophils, form important compartments for circulating vascular endothelial growth factor. Angiogenesis 2003;6:283287.

15. Kut C, Mac Gabhann F, Popel AS. Where is VEGF in the body? A meta-analysis of VEGF distribution in cancer. $\mathrm{Br}$ J Cancer 2007;97:978-985. 